\title{
No-till Vegetable Production-Its Time is Now
}

Ronald D. M orse

\begin{abstract}
AdDitional INDEX WORDS. conservation tillage, residue management, high residues
Summary. Advantages of no-till (NT) production systems are acknowledged throughout the world. D uring the 1990s, production of N T vegetable crops has increased for both direct seeded and transplanted crops. Increased interest in reduced-tillage systems among research workers and vegetable growers is attributed to: 1) development and commercialization of N T transplanters and seeders, 2) advancements in the technology and practice of producing and managing high-residue cover crop mulches, and 3) improvements and acceptance of integrated weed management techniques. R esults from research experiments and grower's fields over the years has shown that success with N T transplanted crops is highly dependent on achieving key production objectives, including: 1) production of dense, uniformly distributed cover crops; 2) skillful management of cover crops before transplanting, leaving a heavy, uniformly distributed killed mulch cover over the soil surface; 3 ) establishment of transplants into cover crops with minimum disturbance of surface residues and surface soil; and 4) adoption of year-round weed control strategies.
\end{abstract}

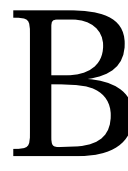

enefits of conservation tillage in general and no-tillage (NT) systems in particular are well documented for many agronomic crops such as field corn (Zea mays L), soybean [Glycine max (L.) M err.], and cotton (Gossypium hirsutum L.) (Carter, 1994; Crosson, 1981; Griffith et al., 1986; Lal et al., 1990). Adoption of conversation tillage systems is increasing in N orth and South America to the extent that it now constitutes the normal or conventional method of crop production for field corn and soybean in some areas (H ebblethwaite, 1997).

\section{Evolution of conservation in the United States}

A major change in tillage practices has required a long transition period because the change involved development and adaptation of new types of equipment and methodology as well as different ways of perceiving the soil ecosystem (Brussard and Ferrera-Cerrato, 1997).

In the early 1900s, moldboard plowing, excessive secondary tillage operations, and multiple cultivations led to serious erosion problems which led to serious flooding and dust storms (Phillips and Phillips, 1984). In 1943, Edward Faulkner boldly challenged the validity and wisdom of using the moldboard plow (Faulkner, 1947). Faulkner asserted: "The truth is that no one has ever advanced a scientific reason for plowing. The entire body of reasoning about the management of the soil has been based upon the axiomatic assumption of the correctness of plowing. 
But plowing is not correct. H ence, the main premise being untenable, we may rightly question the validity of every popularlyaccepted theoryconcerned with the production of any crop, when land has been plowed in preparation for its growth." Although Faulkner was considered a "fanatic" by the academic community of his time, today there is wide acceptance of conservation tillage systems throughout the world.

With the advent of preemergent herbicides in the 1940s, production of agronomic crops such as field corn and soybeansbegan aslow but steady movement toward incomplete, reduced, or minimum tillage - only tilling the soil enough to facilitate plant establishment and subsequent plant growth. Conservation tillage is defined as "any tillage sequence, the object of which is to minimize or reduce loss of soil and water; operationally, it is a tillage or tillage and planting combination which leaves a $30 \%$ or greater cover of crop residue on the surface" (Soil Science Society of America, 1987). N o tillage is theextremeform of conservation tillage where the soil is left undisturbed before planting. Planting is accomplished in a narrow seedbed or slot created by coulters, row cleaners, disc openers, inrow chisels, or roto tillers (H ebblethwaite, 1997). The term no tillage is in reality a misnomer since some tillage or soil loosening occurs from the coulter and the soil-opening devices of the planter (Phillips and Phillips, 1984).

\section{Adoption of conservation tillage systems for vegetables}

Compared to field corn and soybean, adoption of conservation tillage systems for vegetables is still in its infancy stage. Before the 1990s, reluctance to adopt NT techniques for vegetable crops was fueled by several factors.

INADEQUATE EQUIPMENT. U ntil recently, therewereno commercially available N T transplanters and seeders. Any attempt to establish NT vegetables relied on using conventional seeders and transplanters that were not built to handle untilled, high-residue soils.

POOR, UNEVEN STANDS. Inconsistency in obtaining desired plant stands and uniform crop growth hasbeen commonplacein N T vegetableresearch plots and farm fields. M uch of this inconsis- tency can be attributed to use of inappropriate planting equipment and excessive weed growth because of ineffective herbicides (Lanini et al., 1989; Standifer and Best, 1985). Also, when direct seeding into rough, residue-covered soil, small seeded crops such as lettuce (Lactuca sativa L. var. capitata L.) and broccoli (Brassica oleracea L. var. italica Plenck) present greater obstaclesto germination than large-seeded crops, because shallow seeding is required and alleolpathic interference is more severe (Putnam, 1986).

LOSS OF PRECOCITY. Earliness or precocity is often extremely important in the marketing and profitability of many vegetablecrops. O rganic mulches insulate the soil and generally slow early plant growth and delay crop maturity, resulting in loss of precocity (D utton, 1957; H orton, et al., 1994).

Weed control problems. Weedy fields have been a major deterrent to adoption of NT vegetable crops, especially when growers failed to achieve uniformly distributed, high-residue mulched fields. $\mathrm{H}$ istorically, therehave been relatively few labeled herbicides available for production of most vegetable crops, compared to a wideselection for agronomic crops (Standifer and Best, 1985). Therefore, reliance on cultivation to control post-emergence weeds has been a standard practice for production of many vegetable crops. D uring transition from conventional to NT systems, weedy fields have often occurred because most vegetable growers do not have high-residue cultivators.

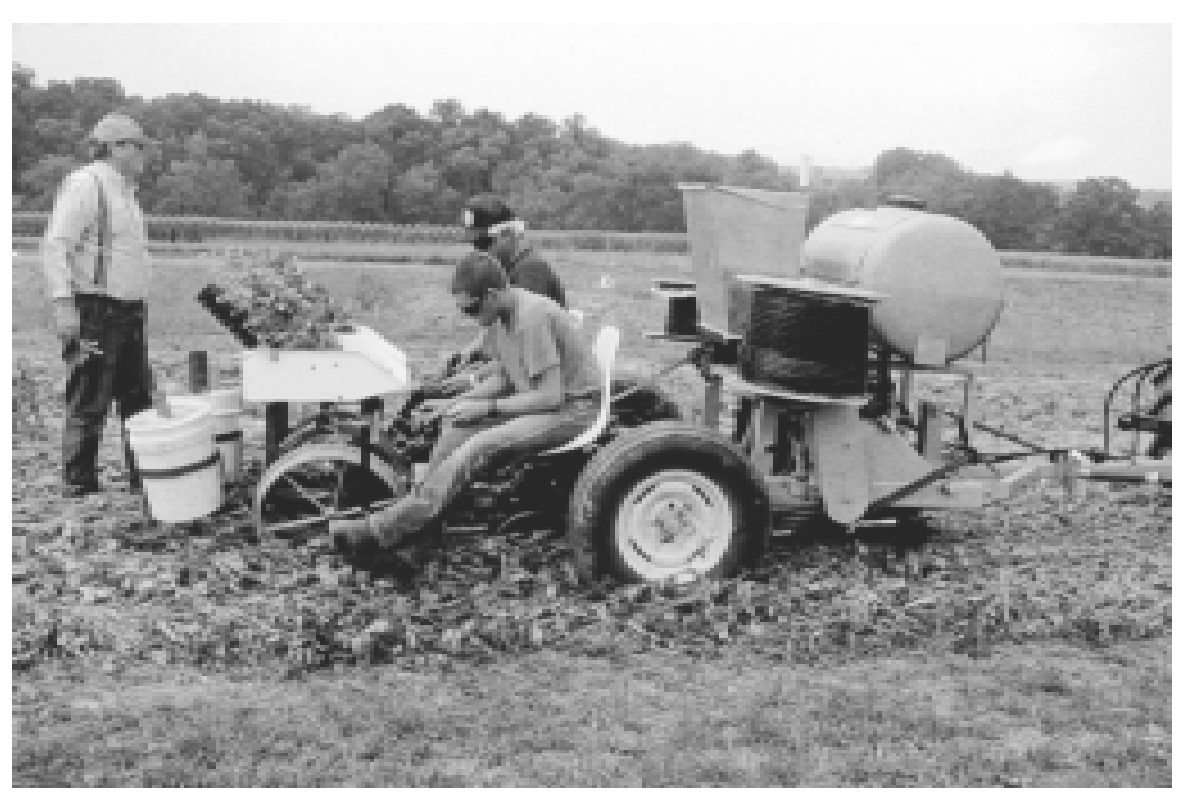

\section{Increase in NT vegetable crops in the 1990s}

Even though crop specific data are not available, interest in and production of conservation tillage vegetable crops haveincreased during the 1990s (Table 1). Although still practiced on a limited scale, there has been considerable increase in adoption of N T for vegetable crops during the past 6 to 8 years (Conservation Technologyl nformation Center, 1997). Recent events and circumstances have contributed to greater acceptance of N T production systems by both the research community and vegetable growers.

AVAILABILITY OF PLANTING EQUIPMENT. For $>40$ years, conventional transplantershavebeen modified to function in untilled fields (M orrison et al., 1973; Rutledgeand D utton, 1999; Worsham, 1985). These NT transplanters have been used mainly by research workers and are not commercially available. In all cases, these NT transplanters have not given consistent resultsin less-thanoptimal conditions. I n compacted and/ or dry soils, reduced plant survival and uneven early plant growth have often occurred, because, without an upfront in-row soil loosening device, proper soil depth placement and subsequent rootsoil contact havebeen difficult to achieve.

NT transplanters and seeders are now commercially available that have been successfully used in many states to

\section{Fig. 1. T wo-row subsurface tiller- transplanter (SST-T) equipped with fertilizer applicators and drip layers.}




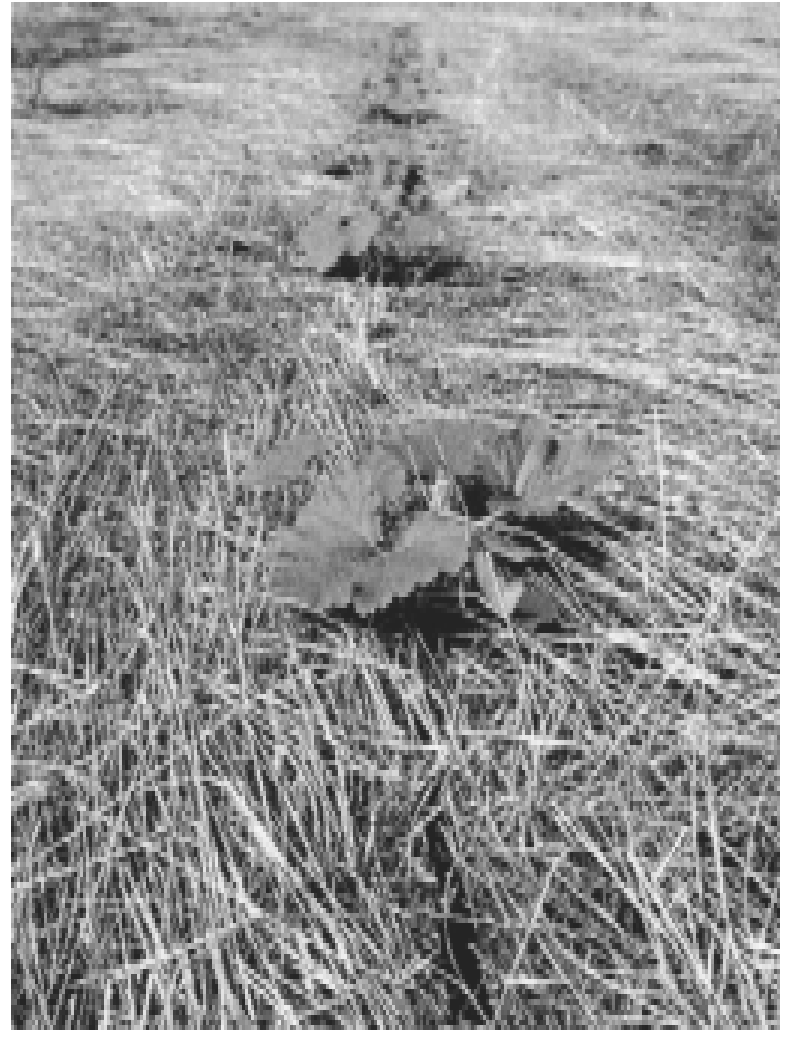

Fig. 2. Row of no-till pumpkins 3 weeks after transplanting; transplants were established, fertilizer was applied, and drip tubing was installed with minor disturbance of surface soil and in situ surface mulch.

establish vegetable crops in high-residue, NT systems (M orse et al., 1993; M orse, 1999). O ne of themost successful units is the Subsurface Tiller-T ransplanter (SST - T) manufactured by B \& B N o-T ill (L aurel Fork, VA). The SST-T is a two-component system, combining subsurfacesoil loosening and transplanting to alleviate soil compaction and effectively set transplants in one operation (Figs. 1-4). TheSST -T hasaunique subsurface tiller (SST) aligned in front of the double-disk shoe of theN T transplanter. Both component function are accomplished with minimum disturbance of surface residuesand surfacesoil (M orse et al., 1993).

Available NT transplanter such as the SST-T are equipped for precision placement of 1) liquid starter fertilizerpesticide solutions around the root system of thetransplant, 2) liquid or granular fertilizers underneath the transplant, 3 ) granular fertilizers surface applied in bands on both or either side of the transplant row, and 4) drip tubing at selected depths below the crop residues and in close proximity of the crop row.
In the 1980s, striptill systems for vegetable crops were explored by $\mathrm{N}$ orth Carolina and Virginia researchers in the attempt to rectify the soil compaction and the resulting poor plant survival associated with the existing NT transplanters. Two-pass, strip-till systems were developed using a Bushhog Ro-till machine (Bushhog, Selma, Al) (H oyt, 1985; M orse, 1989) or a lightweight modified version of the Ro-Till (Wilhoit et al., 1990) to till a narrow strip [ 8 to 12 inches ( 20 to $30 \mathrm{~cm}$ ) wide] followed by a subsequent operation using a conventional transplanter for plant establishment. Therow-till machineseffectivelyloosened in-row soils, resulting in excellent survival, growth, and yield of the vegetables tested; however, this more expensive two-pass system did not find favor with the farmers. In the relatively wide-tilled strip, the soil was exposed and weed seeds were brought to the surface, resulting in decreased soil and water conservation and increased weed problems, compared with NT systems.

In many states, successful NT direct seeding of vegetablecrops has been achieved either 1 ) by using NT seeders built for agronomic crops, in which appropriate seed plates were used for vegetable crops; and/ or 2) by mounting coulters, trash cleaners and other standard NT devices ahead of precision vegetable seeders that enabled seeding and stand establishment in untilled or reduced-tilled soils. With the possible exception of pumpkin (Cucurbita pepo L.), in most instances low-residue crop management has been used with direct seeded vegetable crops. Research is needed to evaluate NT direct-seeded systems for vegetable crops grown in rotation with well established and properly managed high-residue cover crops.

USE OF HIGH-RESIDUE COVER CROPS AND EFFECTIVE RESIDUE MANAGEMENT TECHNIQUES. $\mathrm{H}$ istorically both NT researchers and farmers were reluctant to invest the requisite expense, time, and risk to produce and manage highresidue cover crops for production of agronomic crops. H owever, stimulated by the desire for reduced nonchemical weed suppression and improved produce quality, high-residue, NT systemsfor soybeans (R eeves et al., 1997) and transplanted vegetable crops (M orse, 1995) havebeen developed in which proper growth and management of cover crop residues has been preeminent for success. Associated development of equipment capable of planting into high residueshasallowed successful production of soybean and

Fig. 3 (cover photo). Threerow subsurface tiller-transplanter (SST $T$ ) setting cabbage transplants on Linford Belcher's farm in L aural Fork, Va. 


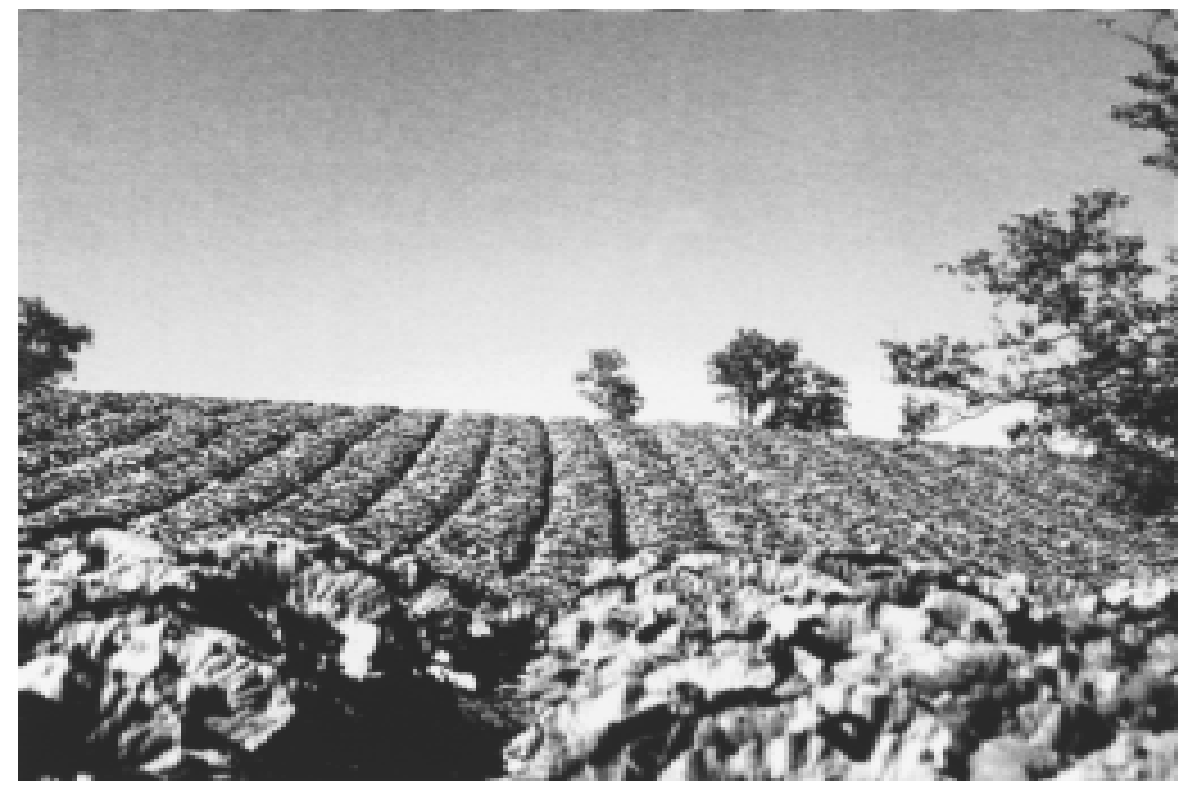

Fig. 4. M ature no-till cabbage in a typical hillslope field near L aural Fork, Va.

many vegetable crops in high-residue, well-managed NT systems.

LABELING EFFECTIVE HERBICIDES FOR VEGETABLES. $M$ any researchers and farmers have shown that the combination of producing and maintaining uniformly distributed, high-residue covers and timely use of both preemergence and postemergence herbicides can provide equal or even better weed control than that achieved in conventionally tilled systems (Abdul-Baki et al., 1997; H ackett, 1998; M orse, 1995). I mprovementsin the formulation and labeling of glyphosate [ $\mathrm{N}, \mathrm{N}$-bis(phosphonomethyl)glycine] and other herbicides (H ackett, 1998) for vegetables have enabled growers to successfully control weeds in N T vegetable production systems.

\section{NT transplanted vegetables in the 1990s- Keys to success}

Reducing or minimizing tillage (particularly inversion of the soil, using themoldboard plow, disk, etc.) increases soil organic matter content, which in turn increases soil quality (D oran and J ones, 1996; I smail et al., 1994). From the perspective of both the farmer and the soil scientist, in situ production and retention of high levels of crop residues (high-residue farming) on untilled soil (NT) is the most cost- and time-effectiveway of increasing soil organic matter (Crovetto, 1996). Indeed, high-residue/
NT (H R/ NT) farming systemscan play a major role in achieving a sustainable agricultureworldwide(L al et al., 1990).

$\mathrm{H}$ igh-residue covers can interfere with seed germination and seedling growth, reducing the chance of achieving adequate plant stands with directseeded crops. C onversely, proper establishment of large, vigorous transplants minimizes crop interference and dramatically increases the change of plant survival in high-residue covers. In addition, using transplants favors rapid canopy closure and weed suppression, reducing the need for chemical weed control (M orse, 1995).

$\mathrm{H}$ igh, profitable yields are achievableusing H R/ N T production systems. Growers should use a year-round systems approach in HR/NT farming. Success depends on 1) selecting the most sustainable or appropriate crops, cultivars, soils, and microclimatic conditions and 2) identifying and applying yield-enhancing practices inherent or specific for H R/ NT systems. The remainder of this paper will focus on the latter: yield-enhancing practicesspecific for HR/ NT systems. In the sections that follow, four production strategies (objectives) are briefly presented, emphasizing proper use of available equipment and associated technology.

\section{Objective I: Produce a dense, uniformly distributed cover crop before transplanting}

Sparse, unevenly distributed crop residues is a major cause of poor results in NT transplanted crops. In contrast, establishing a dense, uniformly distributed cover crop before transplanting providesthegreatest chance for success. Benefits from heavy, evenly distributed residues include weed suppression, reducing or eliminating the need for preemergence herbicides; greater conservation of soil and water; and greater trafficability resulting in improved flexibility in timing field operations.

With NT production systems, investing in cover crop residues before transplanting is like establishing a savingsaccount: you receivethe input (deposit) back plus interest later. Every effort and expense to establish a relatively weed-free, dense cover crop will be rewarded later in the form of improved crop yields and quality. Recommended cultural practices include selecting the most adaptive and compatible cover crops, obtaining a uniform densestand by drilling high seed rates at close between-row spacing and providing adequate growth inputs (water and nutrients) and growing time to maximize cover crop biomass.

\section{Objective II: Kill cover crops before transplanting, leaving a heavy, uniformly distributed mulch cover over the soil surface}

Weedsreduce crop yieldspredominantlybyinterspecific (weed-crop) competition for water, nutrients and light. To minimize interspecific competition, the cover crop must be killed and subsequently managed in such a manner that the in stu mulch effectively covers and shades the soil surface but does not excessively shade or deleteriously affect growth of the transplanted crops. Either chemical and/ or mechanical methodscan be used to kill and retain a dense uniformly distributed mulch ( $D$ abney et al., 1991; M orse, 1995).

Chemical methods. Contact herbicides such as glyphosate and paraquat (1,1'-dimethyl-4,4'-biphyridinium ion) are needed to desiccate perennial and immature annual weed and cover crop species. D esiccation should be done 2 to 5 weeks before transplanting to ensurecompletevegetativekill. G lyphosate should beapplied at least 4 weeksbefore transplanting to avoid any potential stunting of the transplanted cropsfrom root-to-root transfer of activeglyphosate exuded from roots of the treated cover crop to the roots of the transplanted crops. Often two or more sprays are 
Table 1. Feasibility ${ }^{2}$ of achieving successful production of vegetable crops, using no-tilly ${ }^{y}$ production systems.

\begin{tabular}{|c|c|c|c|}
\hline \multicolumn{2}{|c|}{ Vegetable crop } & \multicolumn{2}{|c|}{ Planting method } \\
\hline Botanical name & Common name & Direct seeded & Transplanted \\
\hline Zea maysL. & Sweet corn & $\mathrm{High}$ & $\mathrm{NA}$ \\
\hline Brassica sp. & Cabbage, broccoli, cauliflower, collard & Low & $\mathrm{H}$ igh \\
\hline Cucurbita sp. & Pumpkin, summer squash, winter squash, gourds & $\mathrm{H}$ igh & $\mathrm{H}$ igh \\
\hline Cucumissp. & Muskmelon, honeydew melon, cucumber & $\mathrm{H}$ igh & $\mathrm{H}$ igh \\
\hline Capsicum annuum L. & Bell pepper, cayenne pepper & Low & $\mathrm{H}$ igh \\
\hline Lycopersicon esculentum M ill. & Tomato & Low & $\mathrm{H}$ igh \\
\hline Solanum tuberosum L. & Potato ${ }^{x}$ & M oderate & $\mathrm{NA}$ \\
\hline I pomoea batatasL. & Sweetpotato & NA & M oderate \\
\hline
\end{tabular}

zF easibility based on past and current observations in research plots and grower fields. In many cases, grower experience has been limited to small-scale [ <25 acres ( 11 ha) ] fields. Feasibility ratings: high = broad-scale success achieved by both researchers and growers; moderate = experience limited mainly to small-scale research plots; low =not currently recommended because of insufficient research and/ or grower experiences; NA = not applicable because planting method is not commonly practiced.

y o-till includes strip-till systems.

xFor potato, whole seed tubers or cut seed tuber pieces are planted.

required to completely desiccateall vegetation.

Mechanical methods. M any species of mature annual grass and legume cover crops can be effectively killed using mechanical methods(M orse, 1995). To be successful, however, mechanical treatments must occur after the annual species have developed beyond their vegetative stage and ideally after flowering. When attempting to kill mixtures of annual species (cover crops and/ or weeds) mechanically, all species should be mature and incapable of regrowth following mechanical treatments. M echanically killing cover crops has two distinct advantages over using contact herbicides: 1) negative environmental impacts of herbicides are reduced; and 2) cover cropscan bekilled immediately before planting, which maximizes the growth potential and maturation of the residues. Sincea relatively high percentage of transplanted crops are irrigated, potential soil moisture depletion problemsarising from drought before planting are negated.

Flail mowing and rolling have been used effectively to kill black oat (A vena strigosa Schreb.), cereal rye (Secalecer eale L.), wheat (Triticum aestivum L.), foxtail millet (Setaria italica L.), buckwheat (Fagopyrum saggitatum G rlib.), crimson clover(TrifoliumincarnatumL.), and soybean (M orse, 1995; Reeves et al., 1997). Flail mowing effectively kills most matureannual cover cropsand distributes a uniform layer of organic mulch over the soil surface. Rotary mowersarenotrecommended becausetheytend to windrow the chopped residues. Flail mowers contain many small double-edged knives affixed to a parallel rotor that uniformly distrib- ute the finely cut residues over the soil surface.

Rolling can effectively kill many cereal grain crops and some legumes. Cover crop kill is often less complete when rolled than when mowed. $\mathrm{H}$ owever, the NT transplantersfunction better and cover crop persistence and weed suppression are better in rolled than in mowed plots (M orse, 1995).

When rolled effectively, dense stands of mature annual cover crops are laid prostrateuniformlyover theground and remain lodged. Complete kill takes from a few days to several weeks, and in some cases partial greening may remain throughout the growing season of the transplanted crop. With most crops, however, any interspecific competition between the transplanted crop and the living cover is not a serious yield-limiting factor and is more than compensated by the many growth-promoting benefits of rolled, heavy crop residue mulch. Planting the transplanted crops in multiple rows often helps considerably to minimize greening of the follow cover crops and thus reduces interspecific competition effects.

$M$ anytypesof equipment havebeen used to roll mature annual cover crops, including

1) Disengaged flail mower. When disengaged and pulled over theground, the roller gauge wheel of the flail mower can effectively flatten mature crop residues (M orse, 1995).

2) Grain DRILLs. M odified grain drills equipped with coulters and castiron press wheels spaced 5 inches $(13 \mathrm{~cm})$ apart have been effectively used to roll some cover crops (D abney et al., 1991).
3) TURF OR CONSTRUCTION ROLLERS. Commerciallyavailablewater-filled rollers used for compacting and rolling turf and roadways could be used to roll crop residues( $\mathrm{H}$ offman et al., 1993).

4) Roller-Crimper DRUm. Water-filled drum rollers modified with horizontal welded blunt steel blades or metal strips have been used in Brazil and other locationsto roll-crimp cover crops, thus facilitating killing yet leaving plant stems intact (Reeves et al., 1997).

5) Undercutter-Roller. A modified bladeplow (V-plow sweep) hasbeen used as an undercutter, designed to sever the cover crop roots, followed by a rolling harrow which rolls the residues flat over the ground. This undercutter-rollerfunctionswell on raised beds under dry, nonrocky conditions (C reamer et al., 1995).

6) Rolling stalk CHOPPer. When properly adjusted or modified, stalk choppers can effectively roll and evenly distributehigh-residuecover crops (H ackett, 1998).

Rolling appears to have considerablemerit for mechanically killing cover crops. O ngoing crop residue management research and field testing in several states (V irginia, N orth Carolina, Pennsylvania, Alabama, M aryland, and California) should help clarify the relative advantages and specific uses of different rolling methodsfor mechanically killing cover crops in H R/ NT vegetable production systems.

Chemical and mechanical methoDs. The SST-T functions best in upright-standing (intact) residues, regardless of the height of the cover crops. In 
contrast, in some situations the SST -T functionspoorly in lodged desiccated residues or coarsely chopped, unevenly distributed residues such as derived from rotary mowers (M orse et al., 1993). Although the benefits of high residues are many, shading and survival of newly germinated ortransplanted cropscan beproblems in dense, tall-standing residues.

In some situations where contact herbicides are required to achieve an adequatekill of tall-standing cover crops, mowing or rolling may be used to flatten the desiccated residues and minimize shading of the transplanted crop (M orse, 1995). For example, contact herbicides combined with or without preemergent herbicides can be used to desiccate tall-standing, dense residues, followed by mowing or rolling before transplanting or mowing (with mower blades held above the established transplants) after transplanting.

Recently, several cover crops have been effectively killed by first rolling tallstanding covers followed by applying paraquat. Thismethod looksvery promising since rolling orients and flattens upright-standing residues in one direction, which improves transplanting effectivenesswith theSST -T (R.D.M orse, unpublished data).

\section{Objective III: Establish transplants into cover crops with minimum disturbance of surface residues and surface soil}

L ack of reliable NT transplanters and inconsistent stand establishment have been major factors limiting the adoption of N T systemsfor transplanted crops. Generally, low yields soccur when NT is practiced in poorly drained, compacted soils. In NT systems, when a device (chisel plow, coulter, rototiller, undercutter, etc.) is used to loosen or fracture a strip of in-row soil before transplanting, both stand establishment and subsequent plant growth are improved, approaching or even surpassing that achieved in tilled soils. With the recent development of the SST -T, no tillage with in-row soil loosening and transplanting are combined in one pass across the field (M orse et al., 1993).

\section{Objective IV: Practice year- round weed control}

The old adage "an ounce of prevention is worth a pound of cure" is particularly valid in HR/ NT farming.
Weed control can be achieved in two ways-directly using both chemical and mechanical means and indirectly by using cultural practicesthat promoterapid plant growth and canopy closure. Preemergence and postemergence herbicides can be applied and, in conjunction with physical and allelopathic effects associated with high-residue covers, often provide adequate weed control. $\mathrm{H}$ owever, thebest direct method is to lower weed and seed populations before transplanting (i.e., apply aggressiveweed-control measuresbeforeand/ orduring production of the cover crop).

Of critical importance, NT fields should nothaveaseriousperennial weed problem such as nutsedge (C yperusL.), quackgrass [A gropyron repens (L.) Beauv.], johnsongrass [Sorghum halepense (L.) Pers] or morningglory (I pomoea L.). Weedy fields should be cleaned up before seeding the cover crop; and/ or, if necessary, herbicides should be used in conjunction with production of the cover to minimize weed population before transplanting. Appropriate use and timing of pretransplant herbicides to achieve a "stale seedbed" (reduced weed seed population) and adenseweed-freecover crop are generally more environmentally friendly and less expensive than typical uses of herbicides.

The term stale seedbed (more appropriately stale transplant bed) refers to techniques allowing weed seeds in the soil surface to germinate and be killed without redisturbing thesoil other than the seeding operation. Fallowing the NT field before seeding the cover crop and eradicating emerged weeds, either by mowing or with herbicides, followed by N T drilling cover cropsisan excellent way to obtaining both a stale seedbed and a weed-free cover crop before transplanting.

U sing cultural practices that promote rapid plant growth and canopy closure will result in improved weed suppression and higher crop yields. Recommended cultural practicesinclude1) using large, vigorous transplants; 2) arranging plants in multiple rows; and 3 ) precision placing and timing of fertilizer and irrigation water.

\section{Literature cited}

Abdul-Baki, A.A., R.D. Morse, T.E. D evine, and J.R. T easdale. 1997. Broccoli production in forage soybean and foxtail millet cover crop mulches. $\mathrm{H}$ ortScience 35:836-839.
B russaard, L . and R . Ferrera-C errato. 1997. Soil ecology in sustainable agricultural systems. Lewis Publ., Boca Raton, Fla.

C arter, M .R. 1994. Conservation tillage in temporate agroecosystems. Lewis Publ., Boca Raton, Fla.

Conservation Technology Information Center. 1997. N ational crop residue management survey. Conserv. Technol. Info. C tr., West L afayette, Ind.

Creamer, N .B., B. Plassman, M .A. Bennett, R.K. Wood, B.R. Stinner, and J. Cardina. 1995. A method for mechanically killing cover crops to optimize weed suppression. J. Alt. Agr. 10:156-161.

Crosson, P.R. 1981. Conservation tillage and conventional tillage: A comparative assessment. Soil Cons. Soc. Amer., Ankeny, Iowa.

Crovetto, C.L. 1996. Stubble over the soil: The vital role of plant residue in soil management to improvesoil quality. Amer. Soc. Agron., M adison, Wis.

Dabney, S.M ., N.W. Buehring, and D.B. Reginelli. 1991. Mechanical control of legume cover crops, p. 146-147. In: W.L. $\mathrm{H}$ argrove (ed.). Cover crops for clean water. Soil Sci. Soc. Amer., M adison, Wis.

D oran, W.J. and A.J. Jones. 1996. M ethods for assessing soil quality. Amer. Soc. Agron., M adison, Wis.

D utton, P.R. 1957. The mulching of vegetables. Tech. Commun. 24. CAB, London.

Faulkner, E.H . 1947. Plowman's folly and a second look. U niv. O kla. Press, N orman.

Griffith, D.R., J.V. M annering, and J.E. Box. 1986. Soil and moisture management with reduced tillage, p. 19-57. In: M.R. Sprague and G.B. T riplett (eds.). $\mathrm{N}$ o-tillage and surface-tillage agriculture. Wiley, N ew York.

H ackett, T. 1998. N o-till, cover cropping sustain vegetable, row crop operation. Conserv. Tillage Dig. (Summer):4-9.

H ebblethwaite, J. 1997. Survey-Environmentally friendly farming eclipses intensivetillage. Partners/ CTIC 15(6):1-4, 13-14.

H offman, M.L., E.E. Regnier, and J. C ardina. 1993. Weed and corn (Zea M ays) responseto hairyvetch ( $V$ icia villosa) cover crop. Weed Technol. 7:594-599.

H orton, R., G.J. Kluitenberg, and K.L. B ristow. 1994. Surface crop residue effects on the soil surface energy balance, p. 143162. In: P.W. U nger (ed.). M anaging agricultural residues. Lewis Publishers, Boca Raton, Fla.

H oyt, G.D. 1985. Conservation tillage 
systems for vegetable production, p. 4447. Pa. Veg. Conf., State College.

Ismail, I., R.L. Blevins, and W.W. Frye. 1994. L ong-term no-tillage effects on soil propertiesand continuouscorn yields. Soil Sci. Soc. Amer. J. 58:193-198.

Lal, R., D.J. Eckert, N.R. Fansey, and W.W. Edwards. 1990. Conservation tillage in sustainable agriculture, p. 203-225. In: C.A. Edwards, R. Lal, P. M adden, R.H . M iller, and G. H ouse (eds.) ). Sustainable agricultural systems. Soil Water Cons. Soc., Ankeny, I owa.

Lanini, W.T ., D .R. Pittenger, W.L. Graves, F. Munoz, and H.S. Agamalian. 1989. Subclovers as living mulches for managing weeds in vegetables. Calif. Agr. 43(6):2527.

M orrison, J.E., Jr., J.H. Smiley, W.O. Atkinson, and D.C. M ilbocker. 1973. A no-tillagetransplanter. H ortScience 17:4446.

M orse, R.D. 1989. Strip tillage is good conservation tillage method Amer. Veg. Grower 37(2):32-33.

M orse, R.D. 1995. N o-till, no-herbicide systems for production of transplanted broccoli, p. 113-116. In: W.L. Kingery and N. Buehring (eds.). C onservation farming: A focus on water quality. Proc. S. Reg. Conserv. T illage Sustainable Agr. Jackson, $M$ iss., 26-28 June.

M orse, R.D. 1999. Affordable small-farm equipment for production of transplanted vegetables in high-residue, no-till farming systems, p. 8-16. In: Emerging soil management options for O regon vegetable production. Salem, O re., 24 Feb.

M orse, R.D., D.H. Vaughan, and L.W. Belcher. 1993. Evaluation of conservation tillage systems for transplanting cropsPotential roleof the subsurfacetillagetransplanter, p. 145-151. In: P.K. Bollich (ed.). The evolution of conservation tillage systems. Proc. S. Conserv. Tillage Conf. Sustainable Agr., M onroe, La., 15-17 June.

Phillips, R.E. and S.H . Phillips. 1984. N otillageagriculture. $\mathrm{V}$ an $\mathrm{N}$ ostrand R einhold, N ew York.

Putnam, A.R. 1986. Allelopathy: C an it be managed to benefit horticulture? H ortScience 21(3):411-413.

Reeves, D.W., M.G. Patterson, and B.E. Gamble. 1997. Cover crops for weed control in conservation-tilled soybean, p. 140-
142. I n: R.N. Gallaher and R. M cSorley (eds.). Proc. S. Conserv. Tillage Conf. Sustainable Agr., Gainesville, Fla., 24-26 June.

Rutledge, A. and P. Dutton. 1998. Experiences with Conservation Tillage Vegetables in T ennessee. H ortT echnology 9(3):366-372.

Soil Science Society of America. 1987. Glossary of soil scienceterms. Soil Sci. Soc. Amer., $M$ adison, $W$ is.

Standifer, L.C. and C.E. Best. 1985. Weed control methods for vegetable production with limited tillage, p. 93-100. In: A.F. Wiese (ed.). Weed control in limited tillage systems. Weed Sci. Soc. Amer., Champaign, III.

Wilhoit, J.H., R.D. Morse, and D.H. Vaughan. 1990. Strip-tillage production of summer cabbage using high residue levels. Appl. Agr. Res. 5(4):338-342.

Worsham, A.D. 1985. N o-till tobacco (N icotiana tobacum) and peanut (A rachis hypogaea), p. 101-126. In: A.F. Wiese (ed.). Weed control in limited-tillage systems. Weed Sci. Soc. Amer., Champaign, III. 